\title{
Urdimento
}

Revista de Estudos em Artes Cênicas

E-ISSN: 2358.6958

\section{Educação e Teatro na Cadeia: Práticas pedagógicas realizadas no Sistema Penitenciário da Papuda/DF}

Janilce Rodrigues

\section{Para citar este artigo:}

RODRIGUES, Janilce. Educação e Teatro na Cadeia: Práticas pedagógicas realizadas no Sistema Penitenciário da Papuda/DF. Urdimento, Florianópolis, v. 3, n. 39, nov./dez. 2020.

DOI: http:/dx.doi.org/10.5965/14145731033920200301 


\title{
Educação e Teatro na Cadeia: Práticas pedagógicas realizadas no Sistema Penitenciário da Papuda/DF ${ }^{1}$
}

Janilce Rodrigues ${ }^{2}$

\begin{abstract}
Resumo
Este trabalho relata algumas práticas pedagógicas realizadas nas oficinas de teatro com internos do Sistema Penitenciário da Papuda, no Distrito Federal. Dialoga com o livro "Teatro em Cadeado - uma experiência em cela de aula", publicado em 2019, como resultado do trabalho desenvolvido entre os anos de 2005 e 2013 nos presídios masculino e feminino. Ao propor possibilidades de liberdade num espaço opressor, a prática do teatro exerceu muitas funções positivas, não somente a expressão artística, mas a desconstrução da identidade marginalizada e oprimida dos presos. O exercício dessa linguagem artística surpreendeu o aluno/preso ao descobrir-se capaz de transformar sua realidade pessimista em um novo olhar para si, protagonizando um futuro libertador e transformador. O teatro, por fim, agiu como elemento humanizador e ressocializador para aqueles que puderam experimentá-lo dentro do sistema penitenciário.
\end{abstract}

Palavras-chave: Educação. Cárcere. Teatro.

\section{Education and Theater in prison - A pedagogical experience}

\begin{abstract}
This article presents the accounts of the pedagogic experience with drama workshops held with inmates of Papuda (DF) Prison System (located in Brazil's capital, Brasilia) between 2005 and 2013. As a result of this work, the book "Teatro em Cadeado - uma experiência em cela de aula, 2019" was written and published. This publication contains experiences with the male and female prison systems and their particularities. The appropriation of the performing language with people deprived of freedom is a psychosocial challenge. By proposing free expression in an oppressor space, the practice of drama has many functions, which is not only the artistic expression, it is the deconstruction of a marginalized and oppressed identity. The exercise of this artistic language amazed the students/inmates when they found themselves capable of transforming their pessimist reality, looking at themselves in a new way, and leading a transforming and liberating future.
\end{abstract}

Keywords: Education. Jail. Theater.

\footnotetext{
${ }^{1}$ Revisão de português realizada por Maria Auxiliadora Franco.

Pós-graduação em Psicopedagogia- Universo (GO). Educação Artística-Universo, Niterói (RJ). Professora Aposentada pela Secretaria de Educação do DF, em 2013. janilcerc@gmail.com
} 


\title{
Educación y Teatro en la Cárcel - Una experiencia pedagógica
}

\begin{abstract}
Resumen
Este artículo presenta el relato de la experiencia pedagógica en talleres de teatro llevados a cabo con reclusos del Sistema Penitenciario Papuda (En la capital brasileña, Brasilia) desde 2005 a 2013. Como resultado de este trabajo se escribió y publicó el libro "Teatro em Cadeado - uma experiência em cela de aula, 2019". En esta publicación se encuentra la vivencia con el presidio masculino y femenino y las especificidades de cada uno. La apropiación del lenguaje escénico con personas privadas de libertad es un desafío psicosocial. Al proponer expresión de libertad en un espacio opresor, la práctica del teatro ejerce muchas funciones, que no es solamente la expresión artística, sino que también la desconstrucción de la identidad marginalizada y oprimida. El ejercicio de este lenguaje artístico sorprendió al alumno/recluso al descubrirse capaz de transformar su realidad pesimista en una nueva mirada para si mismo y protagonizar un futuro liberador y trasformador.
\end{abstract}

Palabras clave: Educación. Prisión. Teatro. 


\section{Apresentação}

Neste artigo compartilho experiências do período em que ministrei oficinas de teatro no Sistema Penitenciário da Papuda-DF como arte-educadora, licenciada em Educação Artística e professora efetiva da Secretaria de Educação do Distrito Federal em convênio com a Fundação de Amparo ao Trabalhador Preso (FUNAPDF). O principal resultado dessa experiência, que vivenciei entre os anos 2005 e 2013, quando me aposentei, foi a publicação do meu livro intitulado Teatro em Cadeado - uma experiência em cela de aula (2019), com o auxílio do Financiamento de Arte e Cultura do Distrito Federal (FAC-DF).

As impressões e experiências descritas neste artigo partem de fragmentos do livro, selecionados em razão do maior impacto percebido por esta autora, nesta oportunidade acrescidos de mais detalhes e percepções pessoais. Tanto o livro como este artigo buscam ampliar o conhecimento existente sobre o sistema carcerário, como também apresentar o impacto e a importância dos projetos arteeducacionais nos espaços das prisões, visto que tais projetos são atividades que em diversas situações se mostram eficientes ao combate à ociosidade dos encarcerados, diminuindo assim a violência e atuando como forma de ressocialização.

\section{O Teatro em Cela de Aula}

Humanizar a cadeia é uma tarefa árdua e contraditória. Instituído para isolar pessoas em conflito com a lei, o cárcere visa, em tese, à privação da liberdade e à reeducação dos condenados. O criminoso é encarcerado por castigo, retirado do livre convívio com a sociedade para "ressocializar". Em seus menores atos, pensamentos e movimentos, o preso é constantemente impedido de ter sua individualidade, com a justificativa de se buscar uma suposta disciplina (Foucault, 1975). Essa forma de controle é comumente chamada justiça. No entanto, não cabe privá-los de direitos humanos e do acesso à educação. 
Foram oito anos dedicados a quebrar os "muros" da cadeia e das "amarras da alma" de todos os envolvidos nos projetos aqui apresentados; e, sobretudo, dedicados a percorrer o caminho da contramão, com a finalidade de promover a liberdade na prisão. O processo construtivo que a atividade artística proporciona é diferente de outras formações e informações; a arte é a formação do interior do homem, é a emoção que ouve a voz do coração, é humanização. Ela é tão importante para o crescimento e desenvolvimento do ser humano quanto a alimentação, a escola, a religião, etc. (Rodrigues, 2019, p. 13). ${ }^{3}$

Utilizar o teatro como forma de aprendizado na prisão é um caminho de aventuras e reflexões, sem manual de instruções. Exige do profissional de educação um olhar para além dos livros ou do arcabouço teórico obtido durante sua formação acadêmica. Chegar ao Setor de Ensino do presídio não é um caminho prazeroso. É preciso coragem e determinação para atuar em um ambiente tão opressor. Procedimentos de revistas ou baculejos, cadeados, grades, criminosos e insegurança constante são elementos que fazem parte do contexto do trabalho na prisão. Uma rotina acompanhada pela sonoplastia das ferramentas que aprisionam o ser humano.

Os jovens do ensino regular nas instituições educacionais comuns entram e saem de salas, escolas, cursinhos que complementam sua formação. Tem a hora do recreio, do lanche. Para os menores, hora de correria, gritaria, brincadeiras etc. Entre os jovens há momento para relatar experiências, informações, hora de acessar suas redes sociais e de se fechar na solidão das telinhas. Não é assim a escola do presídio. São alunos adultos com privação de liberdade. O preso não chega à escola como ele quer. Primeiro ele deve estar instalado no bloco que tem acesso ao setor de ensino, porque já passou pela triagem de segurança. (Rodrigues, 2019, p. 29). ${ }^{4}$

No livro Teatro em Cadeado, afirmo que é possível realizar junto aos detentos, mesmo dentro de um espaço opressor, diversas atividades educativas, tais como: oficinas de teatro, exercícios de expressão corporal, composição e aprendizado de diferentes canções, criações coletivas de textos e de personagens, além da inserção dos jogos e das brincadeiras infantis na prática dessas atividades (Boal,

${ }^{3}$ Sobre a experiência de oito anos como professora dentro do presídio, relatada em Teatro em Cadeado.

${ }^{4}$ Percepções sobre a diferença entre o ensino regular e aquele realizado dentro dos presídios. 
1993). Essa forma de ensino não impacta apenas no aprendizado, mas também no processo de extrapolar os muros da prisão, visto que vários espetáculos foram produzidos e apresentados tanto para o público interno, como também para o público externo, fora do espaço físico da prisão.

Uma das minhas principais constatações trazidas na obra Teatro em Cadeado é a transformação positiva do indivíduo encarcerado. A contribuição que a arteeducação, com ênfase em dramaturgia, proporciona para o preso pode ser percebida em diversas passagens do livro, mostrando a importância desse aprendizado para a humanização dos indivíduos.

As confissões espontâneas, registradas em cartas escritas pelos internos à professora de artes, ressaltam a importância do aprendizado por intermédio da arte para cada um deles. Por considerar que as experiências positivas devem ser compartilhadas e ampliadas, principalmente em se tratando de um assunto tão delicado, essas cartas tornaram-se não apenas a matéria-prima, mas a motivação para organização de Teatro em Cadeado.

\section{Realização dos Espetáculos}

Em 2005 surgiu o projeto O tabaco que mata. O tema foi sugerido pela própria direção da unidade prisional, preocupada com o excessivo consumo do cigarro. A história foi uma criação coletiva dos alunos da oficina de teatro, e a mim coube orientar a escrita e dirigir as cenas. Esse projeto foi apresentado em quatro unidades prisionais e, ao final de cada apresentação, os expectadores puderam esclarecer suas dúvidas sobre os malefícios do tabagismo. Dessa forma, além de obter êxito por estimular a adoção de hábitos mais saudáveis, o projeto também proporcionou diversão e descontração, tanto para aqueles que o produziram, como para aqueles que o assistiram.

Também em 2005, agendado no teatro SESC Garagem, em Brasília, o texto $A$ rotina tornou-se o primeiro trabalho encenado na rua, fora dos muros do presídio. Mais uma vez, os alunos criaram a história, baseada em fatos reais, abordando 
suas rotinas no presídio. O enredo foi construído pelos quatro componentes, que já haviam participado do projeto relatado anteriormente. Nesse momento o aprendizado maior foi meu, a responsável pela oficina.

Para auxiliar na escrita e organização das cenas, foi preciso muito diálogo, com o intuito de compreender melhor aquele universo obscuro e desconhecido.

Os códigos, símbolos, ética e vocabulário próprios do sistema penitenciário começaram a ser desmistificados. Dentro da cadeia, por exemplo, não há tolerância para a cabritagem (traição), também foi necessária muita potoca (conversa) para compreender a realidade da cadeia. A teresa não é uma mulher, e sim o nome de uma corda feita de tecido, utilizada muitas vezes para fuga, ou até para o suicídio. No presídio, nem todos tem acesso a uma jega (cama), para conseguir uma, é preciso muita negociação com os presos mais antigos do barraco (cela). Com as refeições não é diferente: no café da manhã o marrocos (pão) chega junto com o xernobiu/chernobil (café com leite), as xepas são as refeições entregues em pratos de isopor, durante o almoço e o jantar.

Após a devida fiscalização, um momento muito esperado e valorizado dentro da cadeia é o momento de receber o seu catatau (cartas) que é o meio de comunicação do preso com a rua. Essas cartas são lidas por uma equipe do serviço social de cada unidade prisional. As visitas semanais nem sempre são possíveis, seja por motivo de distância, ou pelas diferentes condições socioeconômicas de cada uma das famílias. Sendo assim, a carta manuscrita se torna o grande tesouro da cadeia. Saber redigir e ler uma carta dentro da cadeia se torna um serviço, pago por quem não sabe ler e escrever. Por esse motivo, o valor desse serviço pode ser muito alto.

Somente após entender parte desse vocabulário e realidade próprios daquele contexto penitenciário, o texto $A$ rotina pôde ser desenvolvido adequadamente. Esse texto retrata a chegada de um jovem condenado, sendo apresentado à rotina e à conduta do cárcere por um interno mais velho de cadeia. Assim, o palco foi transformado em um espaço de prisão onde a plateia testemunhou como é a rotina de uma tranca (cadeia). Rotina essa que consiste em tratamento ostensivo 
da segurança, relacionamento entre os internos, sexualidade, horário para acordar e dormir, vocabulário, dia de visita, a cobal (objetos de higiene e comidas autorizados a entrar com as visitas), os apelidos - que são praticamente novas identidades adquiridas dentro do cárcere, religião, cartas, e o abandono da família. Por fim, vários desses elementos de suas rotinas convergindo para uma tragédia, o suicídio. Utilizando também seu vocabulário, os presos empenharam-se em escrever uma história cabulosa (trágica).

Ao final dessa apresentação, a plateia mostrou-se muito emocionada. Algumas autoridades presentes fizeram uso da palavra, ressaltando a importância da ressocialização por meio de arte e educação e salientando que aqueles quatro internos representavam a população carcerária do Sistema Penitenciário da Papuda. Essa foi a primeira experiência de apresentação ao público externo, percebida como um grande sucesso e um enorme aprendizado para todas as partes envolvidas.

O exercício do jogo teatral abriu as algemas. Cada um dos quatro presos teve a oportunidade de, no momento de experimentação, libertar-se do passado que os levou à prisão. A arte liberta! (Rodrigues, 2019, p. 35). ${ }^{5}$

Outra experiência de grande valor, também relatada no livro, aconteceu com alunos das classes de alfabetização. A maioria dos homens da turma apresentava uma aparência pouco saudável, eles eram pobres e de baixa escolaridade. Para essa turma foram propostos jogos lúdicos infantis. Assim, experimentaram brincar de Pique-Pega, Vivo ou Morto, João-Bobo, Escravos-de-Jó e ouviram músicas infantis para brincar com balões coloridos de aniversário. Inspirados no universo infantil, os alunos apresentaram a proposta de encenar algo para o público no pátio, em dia de visita, que, naquele ano, coincidiu com o Dia das Crianças. O texto escolhido foi a fábula $A$ formiga e a neve (Barro, 1995), o mesmo que as professoras regentes estavam trabalhando nas turmas de alfabetização.

A oportunidade de mudar a história, ao se apresentarem como agentes

${ }^{5}$ Percepções do ensino de teatro para alunos presos e das experiências de liberdade vivenciadas por eles, como lido em Teatro em Cadeado. 
do bem estar social, é a catársis. Pode ocorrer dentro do sujeito criminoso que matou, roubou, extorquiu... um sujeito ávido por mudanças que se estabelecem a partir do conhecimento de si mesmo, do uso de sua energia para uma nova forma de vida. (Rodrigues, 2019, p. 35). ${ }^{6}$

A infelicidade do ser humano adulto é ser obrigado a negar a criança que sempre foi. A essência de cada pessoa está na alma da criança que brinca, pergunta, sorri, tem medo, chora e precisa de colo. O núcleo essencial do ego não se modifica, esconde-se por imposições de comportamentos sociais de acordo com a identidade. Em muitos casos, nem a idade é respeitada. São muitas as crianças às quais foi negado o direito de brincar, exercício essencial para um desenvolvimento saudável. Por isso, os presos encontraram liberdade entregandose ao universo infantil por meio dos jogos cênicos.

O Sr. Jair, aos 65 anos, não sabia ler, tinha a aparência e a expressão rude. Depois de participar timidamente das oficinas de teatro, decorou e interpretou muito bem seu personagem: o muro. Ele, realmente parecia um muro ou uma pedra. Desse homem, guardo especial lembrança, e pude observar dia a dia sua transformação. Seu desenvolvimento foi acelerado, melhorou a comunicação verbal com seus pares e seu aprendizado na classe de alfabetização. (Rodrigues, 2019, p. 37). ${ }^{7}$

Outro muro derrubado com as oficinas de teatro foi o próprio preconceito impresso naquelas pessoas, ou seja, como cada um desses indivíduos se enxerga dentro da sociedade. Além da conduta de ética imposta pelas "leis da cadeia", a ausência da educação familiar na formação de cada um é visível. Muitos cresceram nas ruas, à margem da sociedade. As regras de conduta para uma boa convivência em sociedade não fazem sentido para quem nunca esteve inserido nela. O teatro é uma ferramenta que lapida e transforma o homem. Ferramenta essa que devolve ao sujeito sua liberdade e identidade (Boal, 2005).

Para o espetáculo $A$ formiga e a neve, figurino e adereços foram

\footnotetext{
${ }^{6}$ Relato de como a arte educação afeta positivamente as pessoas que podem vivenciá-la, independentemente de suas histórias individuais, como apresentado em Teatro em Cadeado.

${ }^{7}$ Sobre os efeitos positivos do teatro, mesmo para aqueles com pouca instrução, em idade avançada, ou com uma história de vida que suspostamente dificultaria esse tipo de atividade, como lido em Teatro em Cadeado.
} 
confeccionados durante as oficinas de teatro, utilizando materiais disponíveis. Os atores cuidaram pessoalmente de cada detalhe com toda dedicação, capricho e alegria que o projeto merecia. Então, no dia 12 de outubro de 2005, os visitantes apreciaram no pátio a encenação desse espetáculo. Única apresentação, mas de extenso valor para cada um dos atores que, pela primeira vez, executaram um projeto tão valioso. A descoberta de si mesmo é o que a arte proporciona ao ser humano:

O que mais conta num projeto como esse é o processo. A "caixinha" de cada um foi se abrindo em meio a sorrisos e brincadeiras. A máscara do criminoso desaparecendo, dando lugar ao menino desprotegido e entregue ao faz de conta dos jogos. O faz de conta que sou o outro. Brincar é um exercício para a vida. Aos poucos aqueles homens foram libertando a criança que estava presa dentro de si e brincando com ela. Eram três horas diárias de pura liberdade. Não existiam quatro paredes e nem cadeados. Eram meninos brincando e experimentando a liberdade de ser FELIZ. (Rodrigues, 2019, p. 38). ${ }^{8}$

Por constatar que o universo infantil sensibilizou os alunos das oficinas de teatro, outro projeto para crianças foi proposto, desenvolvido e apreciado, mais uma vez fora da cadeia, no teatro da Escola Parque 308 Sul, em Brasília, como parte de um projeto da Secretaria de Educação do Distrito Federal. Uma plateia infantil das escolas públicas assistiu Aconteceu na caatinga (Tavares, 2007), uma fábula com personagens da fauna e da flora nordestina. O texto foi encenado por sete homens utilizando fantoches de luva, confeccionados pela professora. A preparação para essa encenação oportunizou o aprendizado de técnicas relacionadas ao uso da voz e ao manuseio de fantoches. O processo da construção do espetáculo mais uma vez foi grandioso. O primeiro contato com a narrativa estimulou uma conversa saudosa sobre a identidade de alguns presos, filhos de nordestinos que migraram para Brasília no período da construção da nova capital. Assim, dar vida aos personagens da flora e da fauna nordestina se mostrou bastante prazeroso para aqueles que fizeram parte do projeto. Reflexões sobre a vida nordestina também foram levantadas, alimentadas pelo resgate de suas

${ }^{8}$ A experiência de poder reviver a infância, mesmo em situações adversas, e o impacto positivo desse tipo de experimentação com alunos do sistema penitenciário, como lido em Teatro em Cadeado. 
origens e também de suas lembranças familiares.

Personagens como Calango, Cobra, Jurema, Preá, Cardeiro, e Mandacaru receberam alma verdadeira e apaixonada, realizando assim um divertido e interessante espetáculo de fantoches. $\mathrm{O}$ envolvimento com o projeto proporcionou para os presos um momento em que puderam esquecer seu atual contexto, ao mesmo tempo em que resgataram a criança dentro de cada um, criando assim um espetáculo lindo e emocionante.

De volta ao Presídio, os atores relataram a emoção em apresentar o trabalho para crianças, que nem imaginavam quem estava dando vida aos bonecos. As crianças aplaudiram e se divertiram com os fantoches nordestinos e suas músicas. (Rodrigues, 2019, p. 39).9

O resgate às lembranças da infância não foi proposto apenas nas unidades prisionais masculinas, mas também no presídio feminino, ao longo do ano de 2011. As mulheres também puderam experimentar brincadeiras, músicas, danças e histórias infantis que levaram a confissões emocionadas sobre saudades de casa e da família, muitas delas expressas não apenas com palavras, mas através de lágrimas. Para experimentar a dramaturgia, foi realizada a leitura da peça $A$ bruxinha que era boa (Machado,1958), que não pôde ser encenada, pois muitas vezes, devido à natureza do sistema penitenciário, há uma descontinuidade do trabalho, interrompido por diversos motivos de segurança e disciplina. Além disso, fatores externos, como o abandono pela família, influenciam sua baixa autoestima e contribuem para reduzir sua motivação, resultando em baixa adesão das presidiárias às atividades educacionais.

O projeto Conversando com meus botões foi apresentado para um grupo de alunas e foi aceito com entusiasmo. Esse projeto consistia em uma série de poemas de minha autoria, todos relacionados ao universo da costura e atividades afins. "O fio da meada. O fio do tecido. Fio por fio. Tecido macio. Fio de uma longa meada. Longa como a vida que se desfia. É o fio da meada a desfiar a vida." Esse

9 A experiência de apresentar um espetáculo fora do espaço prisional, proporcionando aos atores, presos, vivenciar a liberdade característica do teatro, como lido em Teatro em Cadeado. 
é um dos exemplos de poemas que compunham o projeto.

Alguns objetos próprios da costura foram manuseados pelas alunas. Agulhas, tesouras, linhas coloridas, tecidos e botões pautaram a experimentação e o projeto de encenação. Conversando com meus botões foi agendado e autorizado para apresentação em uma escola do Gama, cidade onde se localiza a Penitenciária Feminina do Distrito Federal, porém, devido à falta de escolta especializada, não se realizou.

\section{A Liberdade Encontrada nas Músicas}

"Quando eu soltar a minha voz, por favor, entenda..." (Gonzaguinha, 1980a). Essa canção ressoa o sentimento de muitos presos perante a sociedade. Cansados das histórias sobre a rotina do cárcere, em 2007, os alunos da oficina de teatro escolheram encenar Gonzaguinha: A ópera de um brasileiro, texto de minha autoria. Para compor o musical, o professor da oficina de música foi convidado a participar junto com seus alunos. Assim, nasceu um projeto interdisciplinar.

As músicas foram ouvidas e apreciadas. Distribuídos os papéis, alguns deles adaptados aos músicos, foram iniciadas as leituras de mesa e os ensaios de cena.

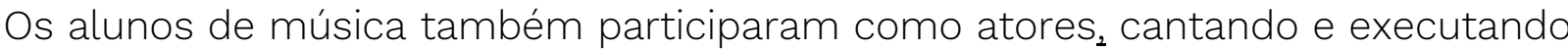
seus instrumentos. Um deles interpretou o próprio Gonzaguinha, protagonista da história.

Sem nenhum financiamento para a produção do espetáculo, foram utilizados materiais recicláveis e doações para confecção da cenografia, figurino e adereços. Parte desse material foi confeccionado pelos próprios presos, que dividiram o horário dos ensaios. A costura ficou por minha conta.

Como grupo de teatro amador, a responsabilidade da produção do espetáculo foi dividida entre todos os participantes. Para aquele grupo de detentos foi um novo aprendizado, novos valores inseridos na vida de cada um. As habilidades individuais foram colocadas a disposição para a construção do espetáculo. Serigrafia, desenho, marcenaria, pintura foram resgatados, deixando 
no esquecimento o carimbo de criminoso. Com entusiasmo e responsabilidade, os alunos participaram integralmente na construção desse espetáculo. Todas as etapas foram debatidas e pensadas pelo grupo. Cada um teve a oportunidade de pensar e concretizar o projeto de forma coletiva. Devido aos rigorosos procedimentos do Sistema Penitenciário, não foi possível obter registros fotográficos dessas etapas, ficaram apenas na memória de quem as vivenciou. Em todos os dias de ensaio, naquela unidade prisional, ecoavam entre as grades e paredes frias, frases como "Eu acredito é na rapaziada..." (Gonzaguinha, 1980), entre outras músicas do Gonzaguinha.

A exibição aconteceu na sala de teatro da Escola Parque 308 Sul, no Distrito Federal. No dia 11 de setembro de 2007, às 20 horas, o Grupo de Teatro Caminho da Liberdade estreou o espetáculo Gonzaguinha: A ópera de um brasileiro. Os treze atores chegaram ao teatro em três viaturas do Grupo de Operações Especiais (GPOE), com apenas alguns minutos de antecedência para o início do espetáculo. Não foi possível nenhum tipo de ensaio naquele palco.

Ao final do espetáculo, aplausos emocionados de uma plateia especial. Professores, autoridades da justiça, familiares dos atores e alguns anônimos. Mais uma vez, "a certeza de ser um eterno aprendiz" (Gonzaguinha, 1982) concretizouse. A satisfação contida em cada um dos integrantes superou a dura realidade das algemas.

Em 2008, como professora da oficina de teatro, efetuei inscrição no projeto Teatro vai à escola da Fundação Athos Bulcão (FUNDATHOS), em Brasília. Esse projeto destinava-se ao desenvolvimento de uma oficina de teatro junto aos professores efetivos da Secretaria de Educação do Distrito Federal, inscritos com alunos da sua unidade escolar. Era, portanto, um trabalho extraclasse e voluntário, dado que os professores e seus grupos deveriam trabalhar em horário disponível fora de sua grade horária escolar.

A equipe técnica da FUNDATHOS ofereceu aos professores suporte artístico e financeiro para a realização de espetáculos de excelência. O projeto inicialmente era destinado aos alunos do ensino fundamental da rede pública, no entanto a 
inscrição dos meus alunos, em caráter especial, foi aceita.

Oito integrantes do Grupo de Teatro Caminho da Liberdade encontravam-se em regime semiaberto, por isso estavam instalados no Centro de Progressão Penitenciária-DF (CPP). Devido a essa situação, somente esses alunos puderam participar do projeto, uma experiência diferente das que estavam habituados. 0 texto trabalhado para apresentação mais uma vez foi o musical Gonzaguinha: $A$ ópera de um brasileiro.

Com melhores condições técnicas, o espetáculo foi revisado, continuando sob a orientação musical do mesmo professor de música. O Festival Teatro vai à escola foi realizado no palco do Centro Cultural Banco do Brasil (CCBB) de Brasília, em novembro de 2008. Os atores chegaram ao local por conta própria, dessa vez livres das algemas. Agora em outras condições de liberdade, tiveram tempo para um ensaio geral no palco onde o espetáculo iria ser realizado.

Cenografia, iluminação, sonoplastia, maquiagem e figurino, tudo foi trabalhado e lapidado para contar e cantar a história de Gonzaguinha no palco do CCBB, sendo que mais uma vez, em seu encerramento, cantamos com o público "Viver e não ter a vergonha de ser feliz, cantar e cantar na certeza de ser um eterno aprendiz...” (Gonzaguinha, 1982).

\section{Afeto e Transformação: O teatro liberta, a educação inclui}

Minha prática pedagógica com oficinas de teatro no cárcere foi um trabalho empírico, intuitivo e sensível ao ambiente diferenciado dos espaços escolares formais. Tomei por base o entendimento de que se não aprendemos, não evoluímos. É fato. Só se aprende fazendo. A ociosidade praticada nos presídios pouco auxilia o preso a pagar sua dívida com a sociedade. O cárcere parece não promover nenhum tipo de diminuição do índice de criminalidade, seja dentro ou fora dele.

Ao trabalhar dentro das unidades penitenciárias não se percebe a existência de políticas públicas de prevenção ao crime. Fora das grades, educadores podem 
constatar em seu cotidiano a devastadora realidade da evasão escolar, enquanto a insegurança nas ruas e a criminalidade em nossas rotinas têm um aumento vertiginoso. Fatos sobre os quais as políticas públicas deveriam se debruçar a fim de buscar alternativas viáveis. A necessidade de investimentos em educação não deveria ficar restrita aos discursos repetidos inúmeras vezes em plataformas de campanhas eleitorais.

A sociedade, formada por seres humanos com sua diversidade, organiza-se e prospera a partir de uma política verdadeiramente amorosa e inclusiva. Ao encarcerado é necessário oferecer ferramentas efetivas de construção e ressignificação de suas vidas, promovendo um novo tipo de conduta para o futuro. Educação é primordial a todos os cidadãos, inclusive aqueles que transgrediram as regras da boa convivência social.

Na cadeia, é comum deparar-se com a triste realidade da negação dos direitos humanos fundamentais. Há relatos de uma infância negada, violada, sem educação, sem afeto. A prisão parece já se encontrar na profundidade desses seres, prematuramente rotulados, tendo negados seus próprios direitos de cidadãos. Marginalizado, o ambiente prisional tende a aumentar o abismo entre as pessoas que se encontram encarceradas e a sociedade. Desumanizados, os presos são vítimas de uma conduta emergencial, sem efetiva expressão de amizade ou fraternidade.

Apesar das restrições próprias da instituição prisional, recebi algum apoio das autoridades locais por reconhecerem que as atividades educacionais influenciavam de forma direta no bom comportamento dos reclusos que delas participavam. Com baixo índice de desavenças e problemas de saúde, esses presos davam "pouco trabalho", conforme relatavam os agentes penitenciários.

O contato com as linguagens artísticas, especialmente o teatro, pode conduzir o homem, inclusive aquele que cometeu crimes, ao retorno às raízes humanas mais profundas de suas memórias. A partir desse momento, o aluno preso é capaz de rever seus valores éticos e morais, tendo conhecimento para reconstruir sua identidade. O teatro liberta e libera emoções contidas pela dor de 
cada um. A entrega às atividades e ao jogo cênico possibilita um esvaziamento do sentimento de violência impregnado na história do indivíduo preso.

Os jogos de fazer de conta possibilitam aos alunos/detentos libertarem o corpo, expressarem emoções, relacionarem-se uns com os outros. Quebrarem o cadeado que os aprisionava em seus interiores. "Por um instante, esqueci em que lugar estava", frase muitas vezes pronunciada por alunos durante as oficinas, retratando que o prazer e a alegria em fazer teatro ressignificou o sentimento de dor que existia em cada um pela condição de estarem encarcerados.

A maioria dos alunos/presos participantes das oficinas alimenta-se da possibilidade de liberdade que o teatro oferece. É quando se abrem os cadeados impostos ao corpo devido a sua condição de aprisionado. Muitas vezes confundindo professores com psicólogos, o sujeito encarcerado descobre, na cela de aula, emoções desconhecidas até então. Encontra dentro de si a liberdade da criação e a beleza que há na linguagem artística.

Não existe transformação sem o trabalho, que é essencial à vida ${ }^{10}$. A dedicação e o zelo em cada trabalho realizado foi a confirmação de que compreenderam a necessidade do conhecimento proporcionado pela arteeducação. A valorização do indivíduo eleva sua autoestima e auxilia no processo de ensino-aprendizagem. O exercício da arte é uma ferramenta transformadora no comportamento do ser humano, em qualquer condição. A arte liberta, quebra cadeados, abre janelas e portas para novos horizontes.

A remissão da pena é o fato que inicialmente motiva os apenados a buscarem as atividades educacionais. As oficinas de teatro inseridas nesse contexto atraíram parte dos encarcerados que vislumbravam a possibilidade de apresentar os espetáculos fora da cadeia. Contudo, tornaram-se, para alguns, oportunidade de descobrirem-se talentosos e admiradores do fazer artístico.

"Pagar cadeia" deixou de ser um peso, ao se dedicarem ao exercício do aprender, apropriaram-se da possibilidade de ressignificação da própria existência e de reconhecimento do erro, para então se redimirem perante a justiça e a

\footnotetext{
${ }^{10}$ No sentido proposto por Fayga Ostrower em Criatividade e Processos de Criação, 2010.
} 
sociedade.

Testemunhei o relato de Severino (aluno que participou do espetáculo "Gonzaguinha"), já em liberdade condicional, quando trabalhava em uma instituição escolar. Ao visitá-lo em seu local de trabalho, relatou-me com orgulho sua nova rotina de cidadão comum: ônibus, vale-transporte, celular, trabalho, família e liberdade! O teatro transforma devido às novas possibilidades de sentir a vida. Portanto, é um grande aliado do Sistema Prisional no processo de reeducação, de ressocialização e de resgate humanizado do sujeito em situação de cárcere.

\section{Referências}

BARRO, João de. A Formiguinha e a neve. 1995.

BOAL, Augusto. 200 exercícios e jogos para o ator e não-ator com vontade de dizer algo através do teatro. Rio de Janeiro: Civilização Brasileira, 1993.

BOAL, Augusto. Teatro do oprimido e outras poéticas políticas. Rio de Janeiro: Civilização Brasileira, 2005.

FOUCALT, Michel. Vigiar e punir: nascimento da prisão. Gallimard, 1975. Tradução de Raquel Ramalhete. Petrópolis: Vozes, 1987.

GONZAGUINHA. E vamos à Luta. Álbum: De volta ao começo. 1980.

GONZAGUINHA. Sangrando. Álbum: De volta ao começo. 1980a.

GONZAGUINHA. O que é o que é? Álbum: Caminhos do Coração. 1982.

MACHADO, Maria Clara. A bruxinha que era boa. 1958.

OSTROWER, Fayga. Criatividade e processos de criação. Petrópolis: Vozes, 2010.

RODRIGUES, Janilce. Gonzaguinha: A ópera de um brasileiro. 2007

RODRIGUES, Janilce. Teatro em Cadeado: Uma experiência em cela de aula. Brasília. 2019.

TAVARES, Clotilde. Aconteceu na caatinga. 2007. 
Recebido em: 15/10/2020

Aprovado em: 05/11/2020 